\title{
MEDICAL IMAGES SEPARATION AND FUSION BASED ON ARTIFICIAL NEURAL NETWORK
}

\author{
Auns Q. H. Al-Neami ${ }^{1}$, Cinan Kanaan A.R. Al Khuzaay ${ }^{2}$ \\ ${ }^{1,2}$ Lecturer / Medical Eng. Dept. / College of Eng. / Nahrain University \\ E-mail: Uns_alneami@yahoo.com ${ }^{1}$, Cinan_med@yahoo.com ${ }^{2}$ \\ (Received: 26/6/2013; Accepted: 21/10/2013)
}

\begin{abstract}
During the last few decades, the field of medical image processing has been closely related to neural network methodologies and their applications. In the present investigation a $512 \times 512$ Computed Tomography (CT) and Magnetic Resonance Imaging (MRI) images for different region of the brain are registered to eliminate the dimensionality differences between the two images, then separated both of them by fast-fixed point algorithm after truncation of each image in to almost 1000 image patches of $15 \times 15$ dimension and transform them to 1-D and order them into row-wise fashion as well as reducing the entered data of lesser interest by Principle component analysis (PCA), finally applying the fusion process using different methods. The result shown that the differently defined brain regions can be separated using batch approaches for both CT and MRI and could be a powerful and accurate diagnostic tool, especially, for surgical and radiotherapy, planning and oncology treatment after a suitable fusion process is carried out on it.
\end{abstract}

Keyword: Bone, Brain Wave, Computerized Tomography, Electroencephalography, Image Processing, X-ray Machine, Magnetic Resonance Imaging.

\section{1- INTRODUCTION}

For medical diagnosis, CT provides the best information on denser tissue with sharp details and less blurring, MRI provides better information on soft tissue with lass and more blurring, and Positron Emission Tomography (PET) provides better information on blood flow and nourishment activity with low space resolution in general ${ }^{[1]}$. With more available multimodality medical images in clinical applications, the idea of combining images from different modalities becomes very important and medical image fusion has emerged as a new and promising research field. The conventional direct image fusion without feature selectivity performed on the collected image proved its incompetence because it gives a general overview of all the fused images, but implementing image segmentation or feature selection 
suitable for each image to extract a unique feature from the collected image results in a single image which can be specified for single application in the same field, taking radiotherapy as an example of CT and MR image. Extracting the tumor from both images and fusing them will be helpful in determining the radiation dose while by extracting the bone boundary from CT image and the soft tissue core from MR image will be useful in determining the radiation direction, it is also useful in 3D surgical planning simulation scenario. The classical methods for feature selection result in error percentage that can be reduced by using intelligent systems such as neural computational models, the one proposed in this thesis is the independent component analysis (ICA) which is a neural statistical computational method of Blind Signal Separation (BSS) which has received a wide attention in various fields such as biomedical signal analysis and processing (Electroencephalogram EEG, Magnetoencephalogram MEG, functional Magnetic Resonance Imaging fMRI), geophysical data processing, data mining, wireless communications, speech and image recognition and enhancement ${ }^{[2]}$.

\section{MEDICAL IMAGING MODALITIES}

For the past three decades medical image modalities grew rapidly and almost drastically changed, it has become smaller, less expensive with low power cost, but the most important thing is it has become more accurate and clearer than before ${ }^{[3]}$. Also, images of a complex object such as the human body reveal characteristics of the object such as its transmissivity, opacity, emissivity, reflectivity, conductivity, and magnetizability, and changes in these characteristics with time. Images that reveal one or more of these characteristics can be analyzed to yield information about underlying properties of the object using only one modality for each characteristic ${ }^{[4]}$.

\section{MULTIMODALITY FUSION USING INDEPENDENT COMPONENT} ANALYSIS (ICA)

Independent Component Analysis (ICA) is a statistical neural method for transforming a combination of observed multivariate (multidimensional) random vectors into components that are statistically as independent from each other as possible ${ }^{[5]}$.

\subsection{ICA Modeling:}

The basic linear representation of the mixing of ICA model is written either in Eq. (3.1) as matrix form or in Eq. (3.2) as column model ${ }^{[6]}$. $\mathrm{x}=\mathrm{As}$ 
Where $\mathrm{A}$ is the mixing matrix with elements $a_{i j}, \mathbf{x}$ and $\mathbf{s}$ are the mixed and source signals respectively. In other hand, $\mathrm{a}_{i}$ are the columns forming A. It would be more realistic to assume that there is some noise in the measurements, which would mean adding a noise term in the model. For simplicity, noise term is omitted in basic model ${ }^{[7]}$. Figure (1) demonstrates the basic linear ICA problem in two forms, (a) general block diagram represented by vectors and matrices, (b) detailed architecture, where $\mathbf{h}(k)$ and $h_{\mathrm{m}}(k)$ are vector and variable of the additive noise, respectively ${ }^{[8]}$. In order to implement an Artificial Neural Network (ANN) for determining ICA, a feedforword fully connected network is required with three or more layers; the first input layer is called whitening (Prewhitening) stage while the second layer is called separation stage and the last one called estimation stage ${ }^{[9]}$. The separation layer is governed by statistical learning rule to change it connection weight $\Delta w$ according to certain algorithm as in Figure (2).

\subsection{Image as ICA Bases Representation:}

Assume that we have a population of patches $\mathbf{I}_{\mathrm{w}}$, acquired randomly from the original image I $(x, y)$. These image patches can then be expressed in lexicographic ordering, as follows:

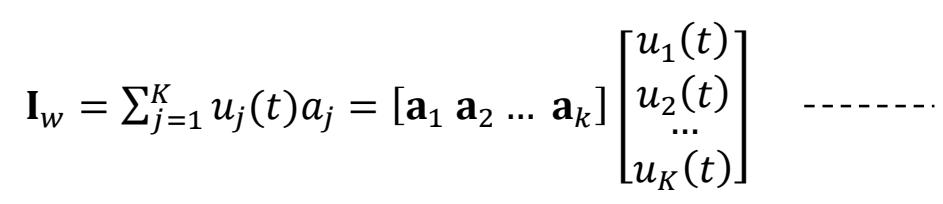

$\mathrm{a}_{\mathrm{j}}$ is a mixing vector, while uj is the source vector. Figure (3) illustrates the whole procedure of image patch selection and lexicographic ordering ${ }^{[10]}$.

Let $\mathbf{A}=\left[\begin{array}{llll}\mathbf{a}_{1} & \mathbf{a}_{2} & \ldots & \mathbf{a}_{K}\end{array}\right]$ and $\mathbf{u}(t)=\left[\begin{array}{lll}u_{1}(t) & u_{2}(t) \ldots u_{K}(t)\end{array}\right]^{\mathrm{T}}$, then, Eq (3.3) can be simplified, as follows:

$$
\begin{gathered}
\mathbf{I}_{w}(t)=\mathbf{A} \mathbf{u}(t) \\
u(t)=\mathbf{A}^{-1} \mathbf{I}_{w}(t)=\mathbf{W} \mathbf{I}_{w}(t)
\end{gathered}
$$

\subsection{Whitening Stage:}

A random, zero-mean vector $\mathbf{z}(k)$ is said to be white if its covariance matrix is the identity matrix, i.e., $\mathbf{R}_{\mathbf{z z}}=\mathrm{E}\left\{\mathbf{z z}^{\mathrm{T}}\right\}=\boldsymbol{I}_{n}$, $\mathrm{E}$ is the expectation value, $\mathrm{R}$ is covariance matrix. In whitening, the sensor vectors $\mathbf{x}(k)$ are pre-processed using the following transformation ${ }^{[8]}$. $\mathbf{z}(\mathrm{k})=\mathbf{V} \mathbf{x}$ 
$\mathbf{y}(k)$ denotes the whitened vector, and $\mathbf{V}$ is an $n \times m$ whitening matrix. If $m>n$, where $n$ is known in advance, $\mathbf{V}$ simultaneously reduces the dimension of the data vectors from $m$ to $n$. In whitening, the matrix $\mathbf{V}$ is chosen so that the covariance matrix $\mathbf{R}_{\mathbf{z z}}=\mathrm{E}\left\{\mathbf{z z}^{\mathrm{T}}\right\}$ becomes the unit matrix $\mathbf{I}_{n}$. Thus the components of the whitened vectors $\mathbf{z}(k)$ are mutually uncorrelated and they have unit variance.

$$
\mathbf{R}_{\mathrm{xx}}=\mathbf{E}_{\mathrm{x}} \boldsymbol{\Lambda}_{\mathrm{x}} \mathbf{E}_{\mathrm{x}}^{\mathrm{T}}=\mathbf{E}_{\mathrm{x}} \boldsymbol{\Lambda}_{\mathrm{x}}^{1 / 2} \boldsymbol{\Lambda}_{\mathrm{x}}^{1 / 2}
$$

where $\mathbf{E}_{\mathrm{x}}$ is an orthogonal matrix and $\boldsymbol{\Lambda}_{\mathrm{x}}=\operatorname{diag}\left\{\lambda_{1}, \lambda_{2}, \ldots, \lambda_{\mathrm{n}}\right\}$ is a diagonal matrix with positive eigenvalues $\lambda_{1} \geq \lambda_{2} \geq \ldots \geq \lambda_{n}>0$.

\subsection{Separation Stage:}

The mixing and filtering processes of the unknown input sources $s_{j}(t)(j=1,2, \ldots, n)$ may have different mathematical or physical models, depending on the specific applications. As mentioned earlier when $m$ mixed signals $x_{i}(t)$ are linear combinations of $n$ (typically $m \geq$ $n)$ unknown, zero mean source signals $s_{j}(t)$ are statistically independent and they are written as $\mathbf{x}(t)=\mathbf{A s}(t)$ which is known as ICA general generative model ${ }^{[8]}$. A fast method for maximizing negentropy than that given by the gradient method can be found using a fixedpoint algorithm. The resulting FastICA algorithm finds a direction, i.e., a unit vector w, such that the projection $\mathbf{w}^{\mathrm{T}} \mathbf{z}$ maximizes non-gaussianity, it is here measured by the approximation of negentropy $J\left(\mathbf{w}^{\mathrm{T}} \mathbf{z}\right)$. Recall that the variance of $\mathbf{w}^{\mathrm{T}} \mathbf{z}$ must here be constrained to unity; for whitened data, this is equivalent to constraining the norm of $\mathbf{w}$ to be unity and by manipulating an algebraic simplification the below equation is obtained.

$$
\mathbf{w} \leftarrow E\left\{\mathbf{z} g\left(\mathbf{w}^{T} \mathbf{z}\right)\right\}-E\left\{g\left(\mathbf{w}^{T} \mathbf{z}\right)\right\} \mathbf{w}
$$

Where $\mathrm{g}($.$) is nonlinear activation function tansh function, \mathrm{g}^{\prime}$ is derivative of $\mathrm{g}($.$) .$ Table (1) summarizes the basic form of the FastICA algorithm, noting that convergence means that the old and new values of $\mathbf{w}$ point are in the same direction ${ }^{[11]}$.

\subsection{Fusion:}

Image registration and fusion is the process of determining the point-by-point correspondence between two images of a scene. By registering two images, the fusion of multimodality information becomes possible, the depth map of the scene can be determined, changes in the scene can be detected, and objects can be recognized. the whole procedure of 
performing image fusion using ICA bases will be discussed, assume that a ICA transform which is denoted by $\mathcal{F}\{\cdot\}$ is already estimated, as described in the previous section.

Let $I_{w}(\mathrm{x}, \mathrm{y})$ be $T M_{1} \times M_{2}$ registered sensor images that need to be fused. From each image isolates every possible $N \times N$ patch using lexicographic ordering, forming the vector $I_{w}(t)$. The patches size $N$ should be the same as the one used in the transform estimation. These vectors are normalized to zero mean; each vector is stored in order to be used in the reconstruction of the fused image. Each of these representations $I_{w}(t)$ is transformed to the ICA domain representation $u_{k}(t)$, assuming that $\mathbf{W}$ is the estimated analysis kernel:

$u_{k}(t)=\mathcal{T}\left\{I_{w}(t)\right\}=\mathbf{W} I_{w}(t)$

Figure (4) illustrates a detailed explanation of the proposed fusion system using ICA bases [10].

\section{RESULTS}

The preparing of the data, registration, separation and fusion are implemented by software model based on MATLAB ${ }^{\circledR}$ program code of version 7.4.0 (R2007a) ${ }^{[12]}$ applied on an Intel based computer of $1.87 \mathrm{GHz}$ processor and $1 \mathrm{~GB}$ RAM. This research demonstrates and discusses CT and MRI head images only as in Figure (5) (a) and (b) respectively. The registration process is concerned which specifying four control points for performing the translation, scaling and rotation as shown in Figure (6) which illustrates (a) CT and (b) MRI images marked with four selected control points of the maximum upper, lower and both lateral curvature.

Figure (7) shows the registration resulted images (a) before registration (b) after the registration. The scaling and rotation differences of the sensed image have been reduced in accordance to the referenced image but the translation was not efficiently done because unsymmetrical distribution of the control point. The extraction process performed using FastICA batch method which explained earlier and the results for the CT image was successfully done in bone regions extraction as demonstrated bellow and for the MRI image the brain white matter, gray mater and the tumor are also extracted. Figure (8) illustrates the extracted bone structure from the CT image. Figure (9) illustrates the extraction of white, gray matter and the tumor of MRI image after 24 iterative learning cycles taking $792 \mathrm{~ms}$ as elapsed time. The fusion process is performed using the weighted combination pixel based fusion which is applied to the CT bone and MRI tumor features as explained earlier. Figure (10) illustrates the fused image of both CT and MRI extracted features. Table (2) shows the 
activity indicator $E_{\mathrm{k}}$ using mean absolute value and $W_{\mathrm{k}}$ for CT extracted bone and MRI extracted tumor that emphasizes feature of more intense activity.

\section{CONCLUSION}

The main conclusions which can be drawn from the results of the MRI and CT are as follows:

The capability of ICA to extracting the bone tissue region rather than the rest of the regions. This is due to the sharpness of the $\mathrm{CT}$ image and the well variation in contrast which give emphasis to the main ICA criterion which is the non-gaussian variable.

The ability of ICA to determine the different brain weighted MRI regions which as explained below:

The white matter is well separated. There .27 are some losses in the gray matter, this is because of the little variation in contrast of gray matter which becomes more Gaussian which inhibits ICA performance leading ICA to consider some pixels as belonging to other regions and are cancelled as noise. Tumor can be considered as CT bone due to its high brightness.

\section{REFRENCES}

[1] W. R. Hendee, "Medical Imaging Physics, Fourth Edition", Department of Biomedical Engineering, Marquette University, USA, 2002.

[2] J. Moore, "Biomedical Technology and Devices Handbook", CRC PRESS, 2004.

[3] V. Kuperman, "Magnetic Resonance Imaging Physical Principles and Application", University of Chicago, 2000.

[4] A. C. Kak, "Principle of Computerized Tomography Imaging", School of Electrical Engineering, P undue University, United State of America, 1999.

[5] A. Hyvärinen and E. Oja, "Fast and Robust Fixed-Point Algorithms for Independent Component Analysis", Neural Networks Research Center, Helsinki University of Technology, Finland, 1999.

[6] A. Hyvärinen and E. Oja, "Independent Component Analysis: Algorithm and Application", Neural Networks Research Center, Helsinki University of Technology, Finland, 2000. 
[7] I. T. Jolliffe, "Principle Component Analysis", Department of Mathematical Sciences, King's College, University of Aberdeen, UK, 2002.

[8] A. Cichicki and S. Amari, "Adaptive Blind Signal and Image Processing: Learning Algorithms \&Applications", Riken Brain Institute, Japan, 2002.

[9] Fredric M. Ham "Principles of Neurocomputing for Science and Engineering", Mc Graw Hill, New York, 2000.

[10] Tania Stathaki, " Image Fusion: Algorithms and Applications", Communications and Signal Processing Group, Imperial College of London, UK, 2008.

[11] A. Hyvärinen et al, "Independent Component Analysis", Neural Networks Research Center, Helsinki University of Technology, Finland, 2001.

[12] S. Westland, "Computational Color Science Using MATLAB", School of Design, University of Leeds, United Kingdom, 2004.

Table (1): The FastICA algorithm for finding one maximally nongaussian direction, i.e., estimating one independent component. The expectations are estimated in practice as an average over the available data sample ${ }^{[11]}$

1. Center the data to make its mean zero.

2. Whiten the data to give $\mathbf{z}$.

3. Choose an initial (e.g., random) vector $\mathbf{w}$ of unit norm.

4. Update $\mathbf{w} \leftarrow E\left\{\mathbf{z} g\left(\mathbf{w}^{T} \mathbf{z}\right)\right\}-E\left\{g\left(\mathbf{w}^{T} \mathbf{z}\right)\right\} \mathbf{w}$, where $g$ and $g$ is defined, e.g. in Eq (3.8)

5. Normalize $\mathbf{w} \leftarrow \mathbf{w} /\|\mathbf{w}\|$.

6. If not converged, go back to step 4 .

Table (2): The Activity Measures for CT Extracted Bone and MRI Extracted Tumor.

\begin{tabular}{|c|c|}
\hline Activity Indicator $E_{\mathrm{k}}$ & 1026.0186 \\
\hline Bone Activity Weight $W_{\text {Bone }}$ & 0.5008 \\
\hline Tumor Activity Weight $W_{\text {Tumor }}$ & 0.4992 \\
\hline
\end{tabular}




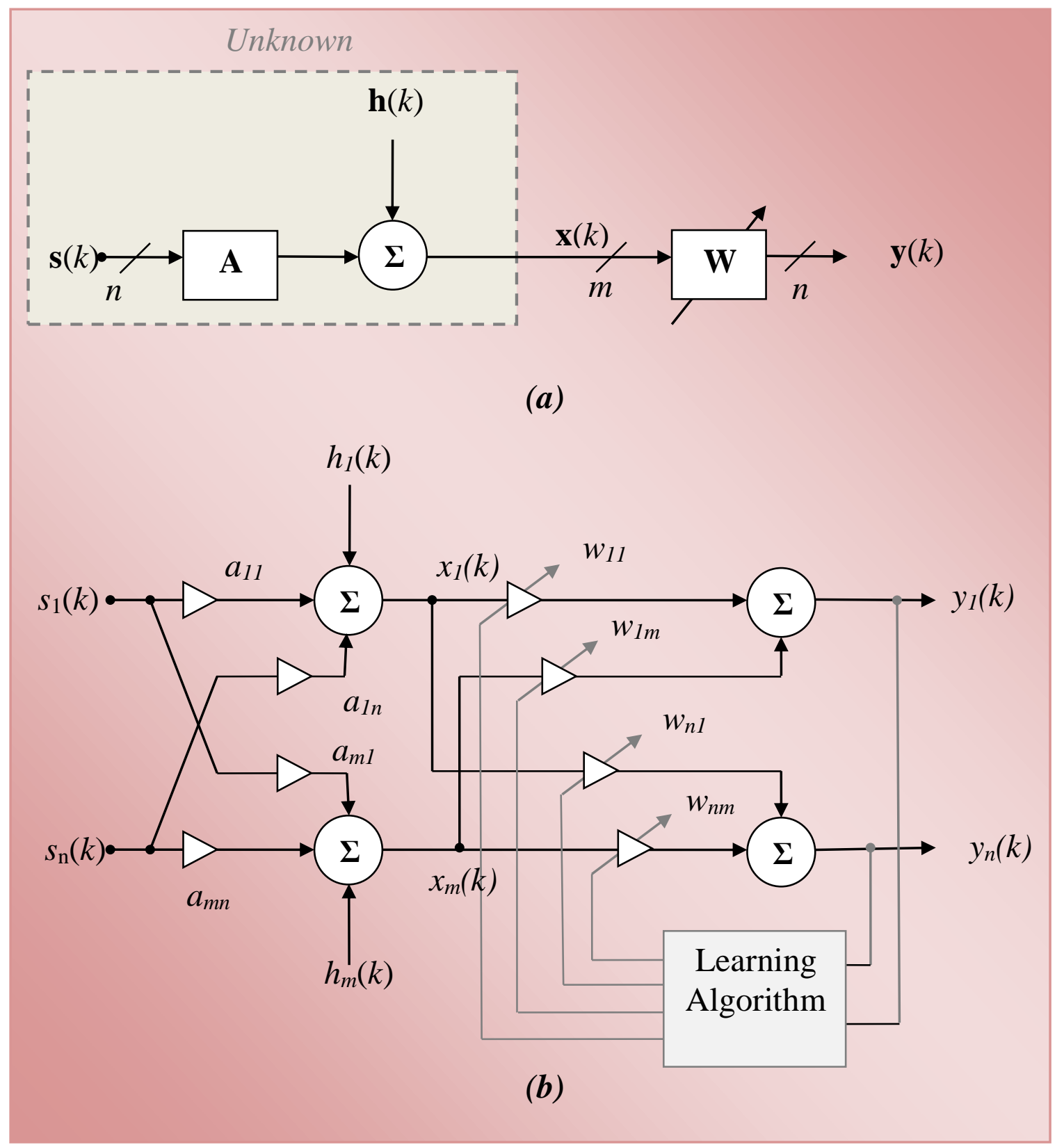

Figure (1): Basic ICA Problem (a) General Block Diagram (b) Detailed Architecture ${ }^{[8]}$. 


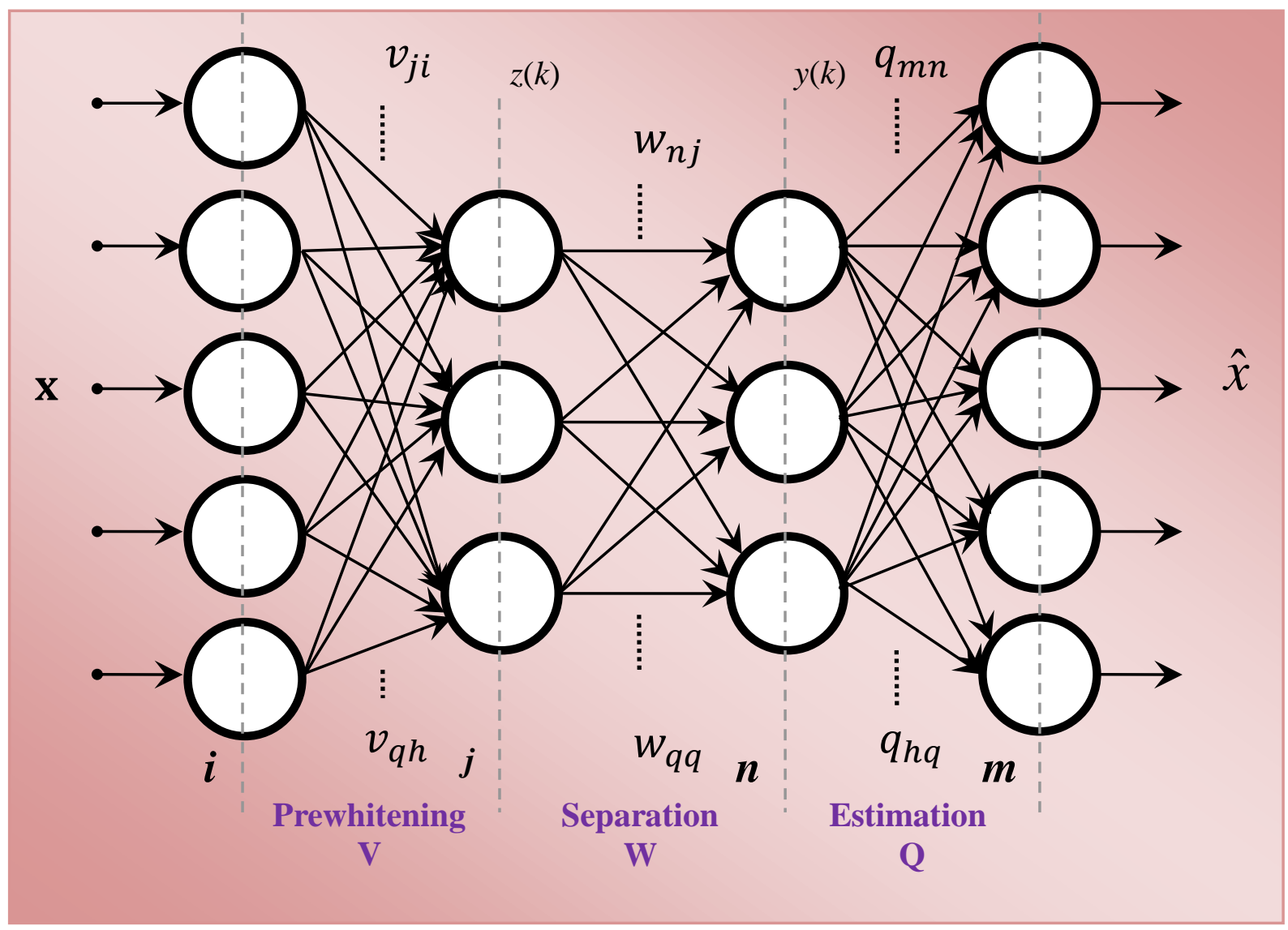

Figure (2): ICA Neural Network Architectural Design ${ }^{[9]}$.

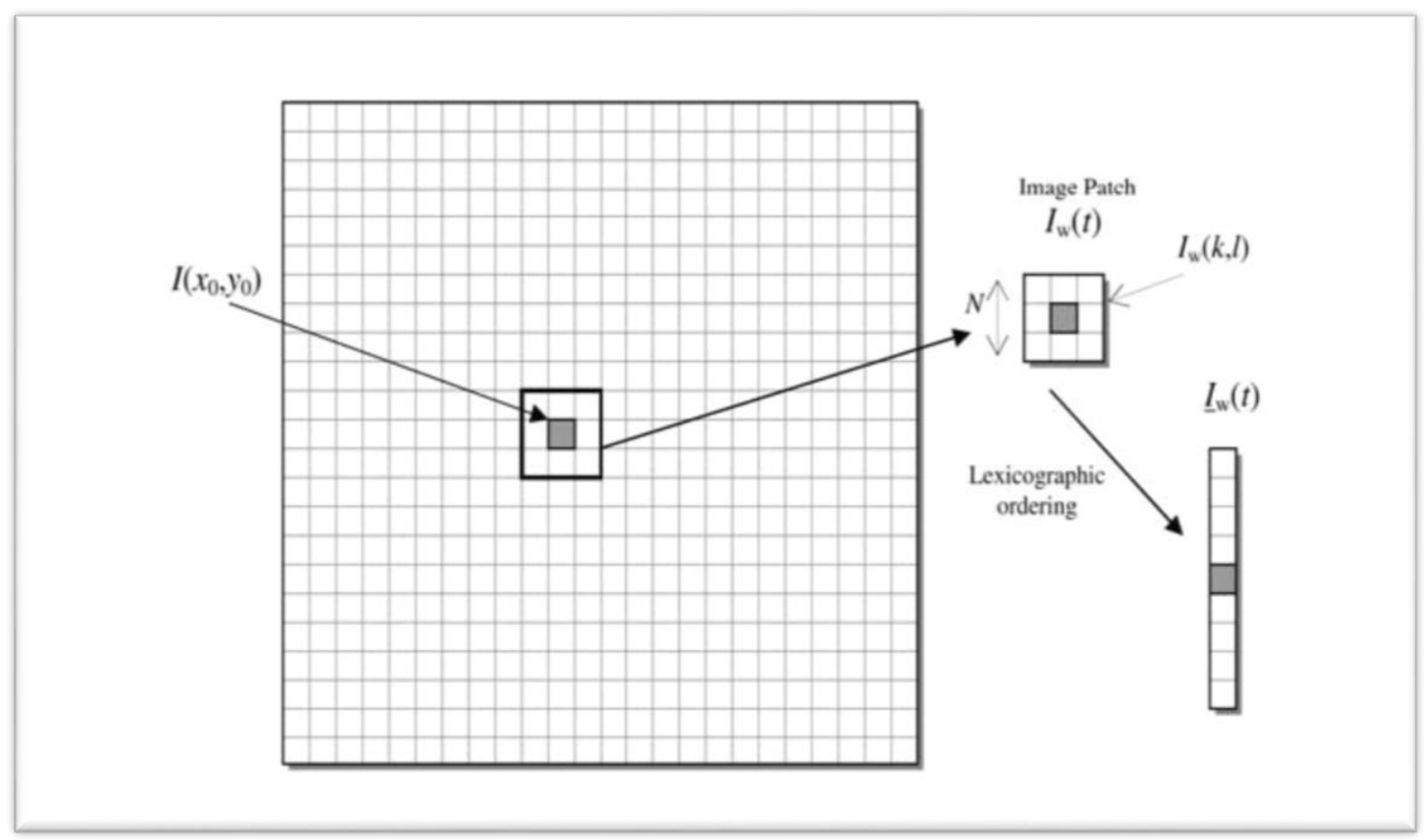

Figure (3) Selecting an Image Patch $\mathbf{I}_{\mathrm{p}}$ around Pixel $\left(x_{0}, y_{0}\right)$ and the Lexicographic Ordering ${ }^{[10]}$. 


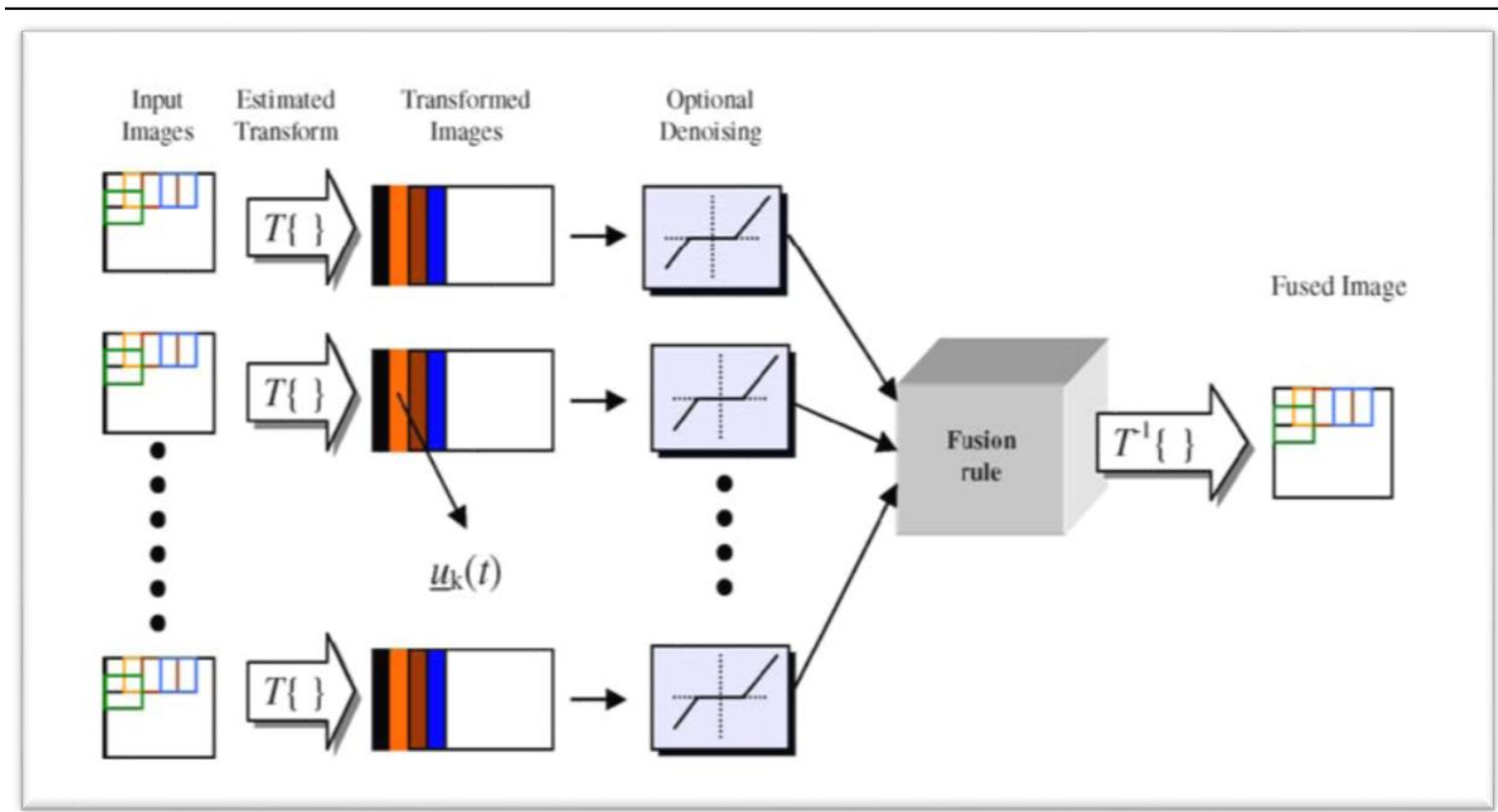

Figure (4): the Proposed Fusion System Using ICA Bases ${ }^{[10]}$
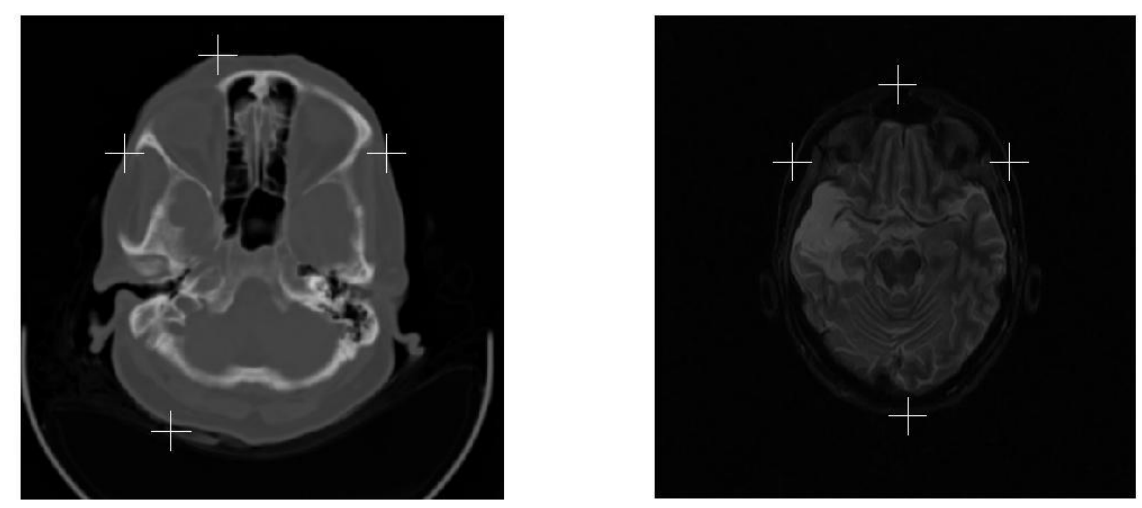

Figure (5): Images with Control Points Marking (a) CT (b) MRI. 


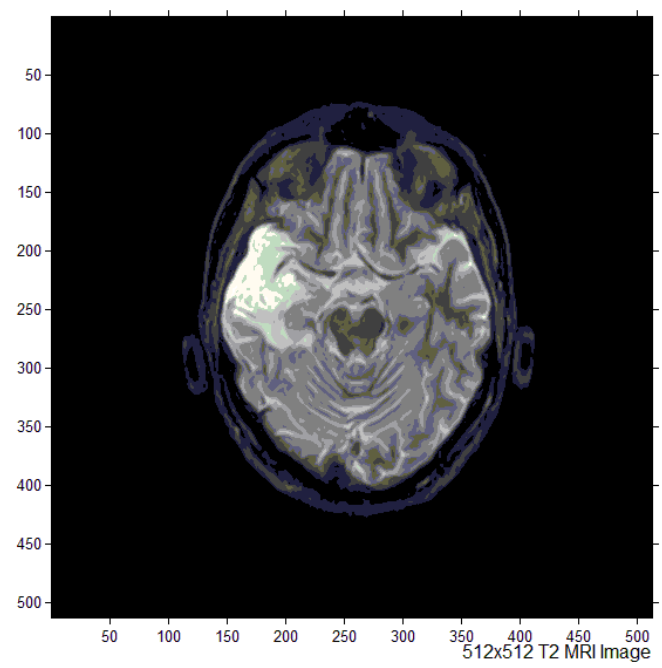

(a)

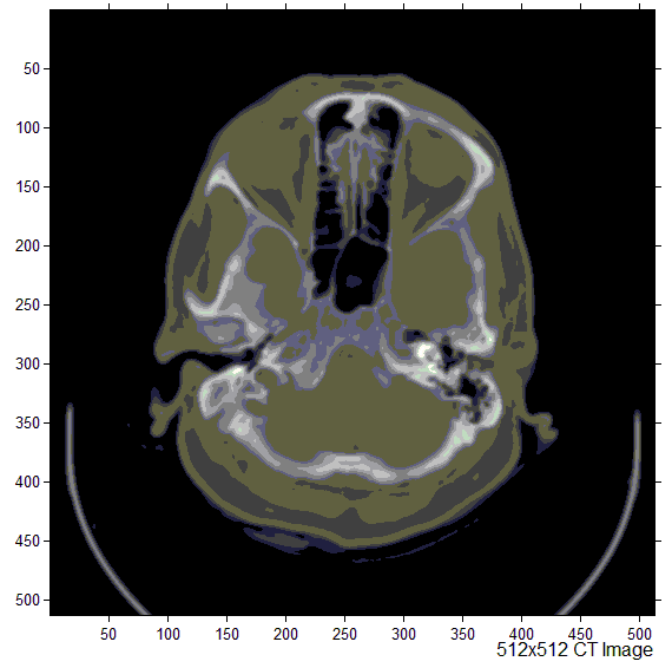

(b)

Figure (6): Registration process images (a) MRI (b) CT.

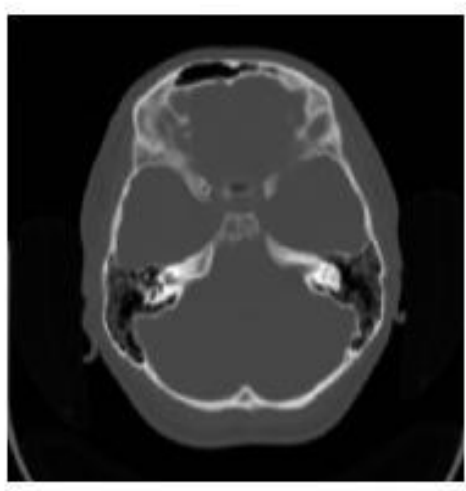

CT

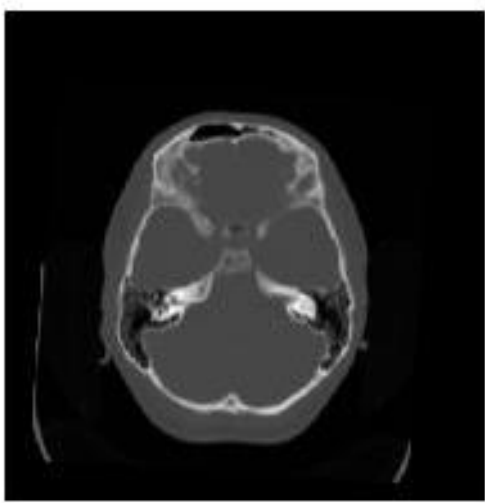

CT

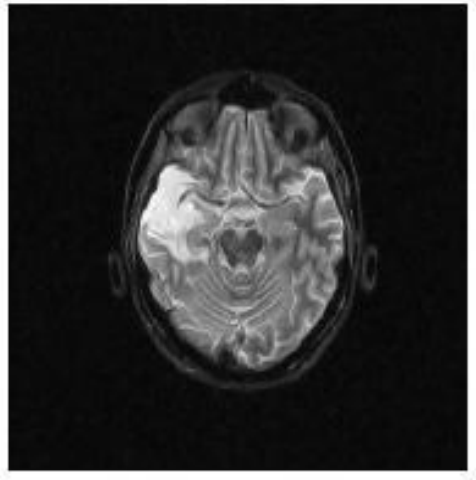

MRI

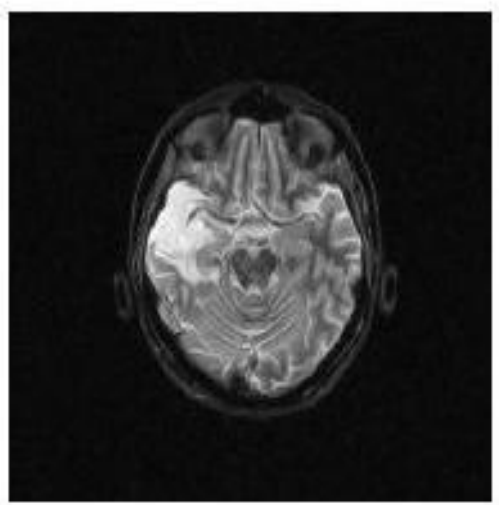

MRI

Figure (7): the Registration Resulted Images (a) Before Registration (b) After Registration. 


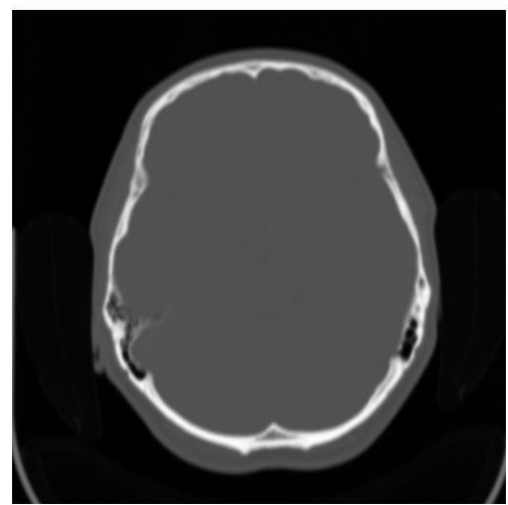

(a)

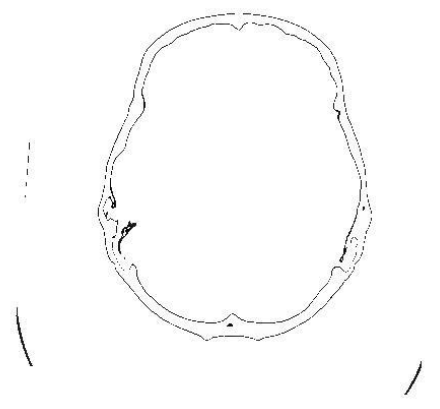

(b)

Figure (8): Separated Bone Tissue from CT Image (a) Original CT Image (b) Extracted Bone Feature.

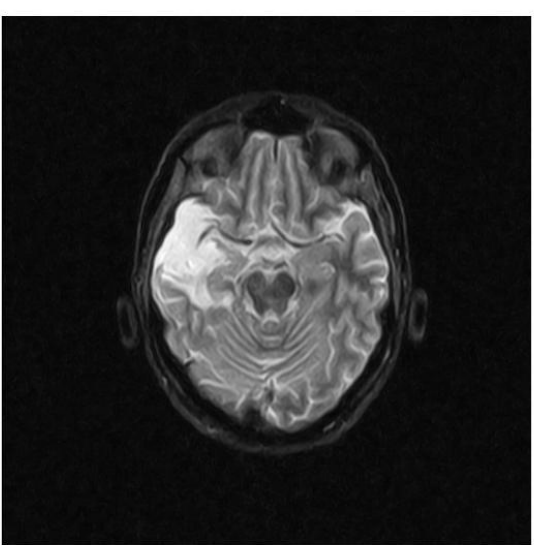

(a)

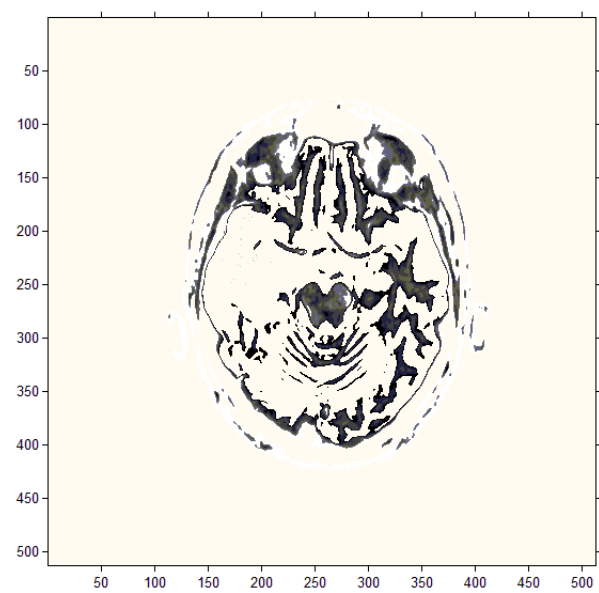

(c)

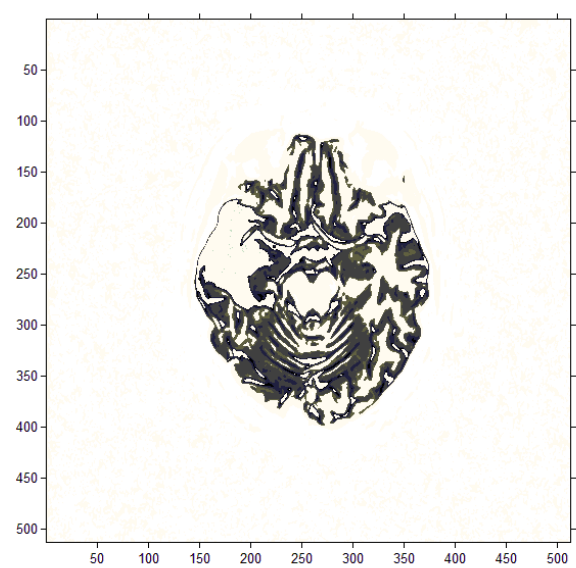

(b)

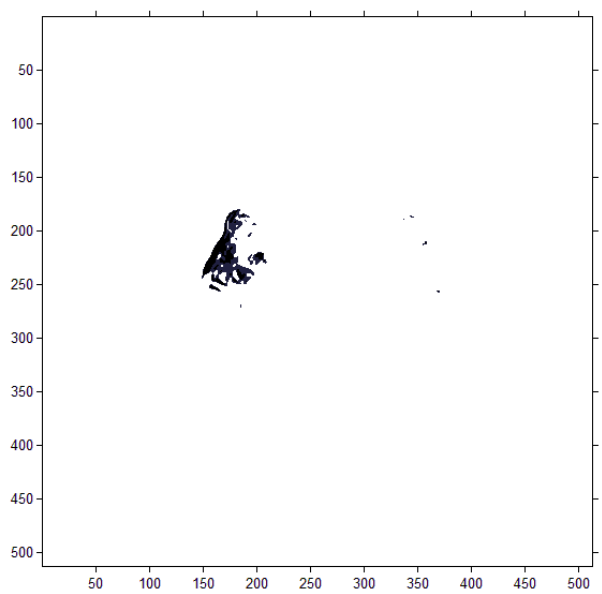

(d)

Figure (9): Separated Bone Tissue from MRI Image (a) Original MRI Image (b) Extracted Gray Matter (c) Extracted White matter (d) Extracted Tumor. 


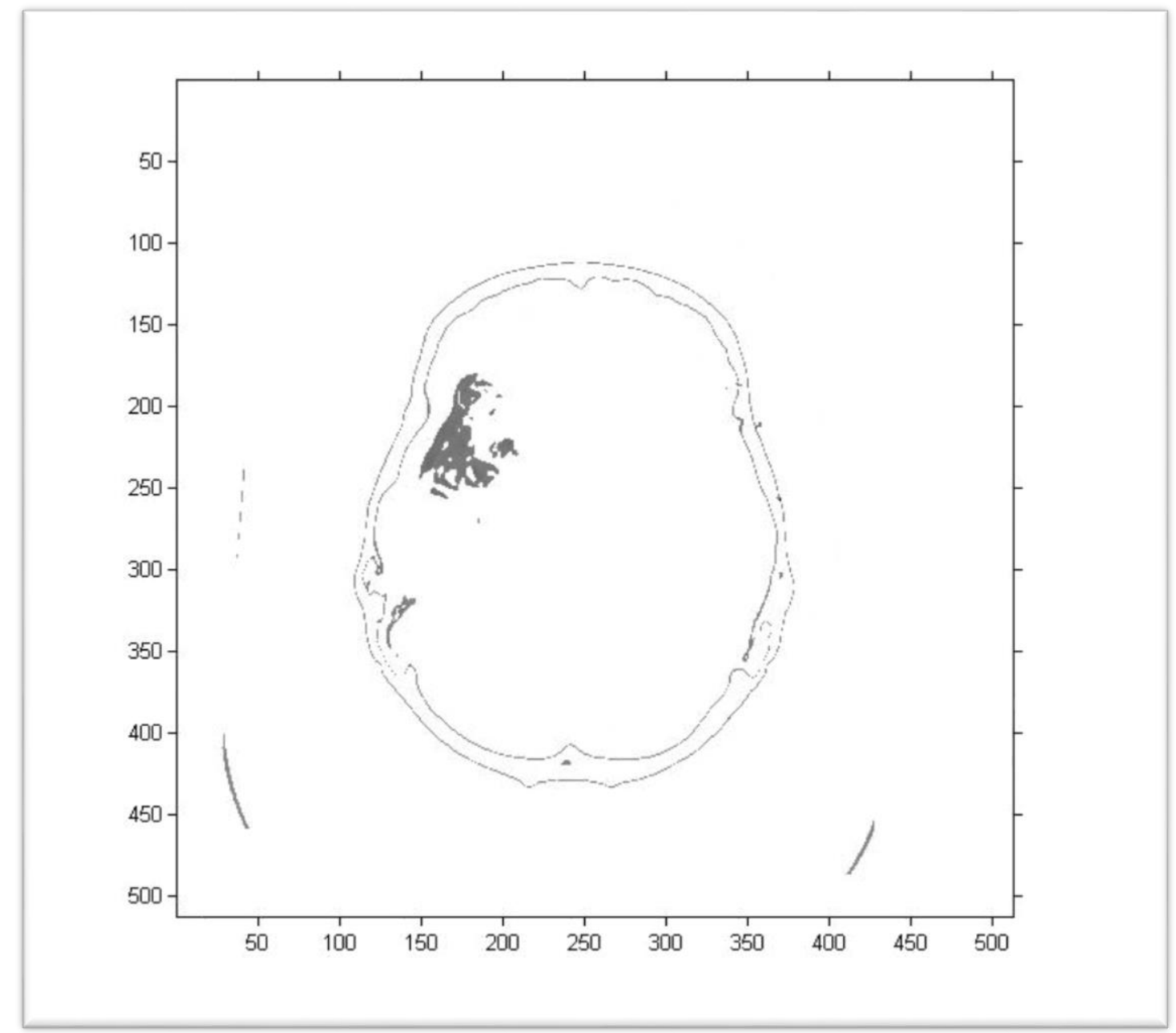

Figure (10): Resulted Fused image of CT and MRI Features. 
فصل ودمج الصور الطبية بالاعتماد على الثبكات العصبية الاصطناعية

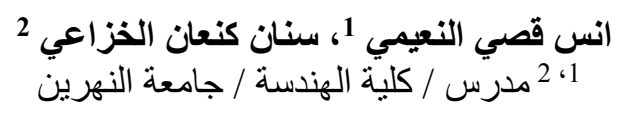

الخلاصة

عبر العقود القليله الماضية أصبح مجال معالجة الصور الطبية ذو علاقة وثيقة بطرق الثبكات العصبية الصناعية و تطبيقاتها و طبقاً للتصاعد الحاصل بالتكنلوجيا و التصوير الطبي. في البحث الحالي ستخزن صورتان لمناطق للدماغ مختلفة ذات ابعاد 512×512 للمفراس الحلزوني (Computed Tomography) و الرنين المغناطيسي ويكي تسجل وتخزن ويحدد الفرق بين ابعاد الصورتين ومن ثم يتم فصلها بأستخدام (Magnetic Resonance Imaging)

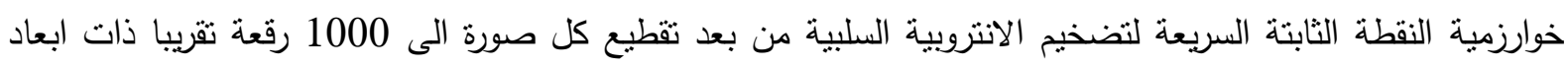
15×15 و تحويلها الى البعد واحد و ترتيبها في نمط صفوف فضلاً عن اختزال المعلومات الغير مهمة بالبيانات الداخلة باستخدام " تحليل المكونات الاساسية" (Principle Component Analysis) لغرض تقليل تونيل التعقيدات الحسابية, و اخيراً تطبيق عملية الدمج باستخدام طرق مختلفة. ان النتائج اظهرت ان مناطق الدماغ المختلفة ممكن فصلها باستخدام الاقتراب الحسابي (Batch Approach) لكلاً من المفراس الحلزوني و الرنين المغناطيسي و من المككن ان تكون اداة تشخيصية قوية و دقيقة, خصوصاً في التخطيط الجراحي و العلاج الاشعاعي للامراض الخبيثة بعد الدمج المناسب. 